\title{
Machinery Faults Detection Using Acoustic Emission Signal
}

\author{
Dong Sik Gu and Byeong Keun Choi \\ Gyeongsang National University \\ Republic of Korea
}

\section{Introduction}

Application of the high-frequency acoustic emission (AE) technique in condition monitoring of rotating machinery has been growing over recent years. This is particularly true for bearing defect diagnosis and seal rubbing (Mba et al., 1999, 2003, 2005; Kim et al., 2007; Siores \& Negro, 1997). The main drawback with the application of the AE technique is the attenuation of the signal and as such the AE sensor has to be close to its source. However, it is often practical to place the $\mathrm{AE}$ sensor on the non-rotating member of the machine, such as the bearing or gear casing. Therefore, the AE signal originating from the defective component will suffer severe attenuation before reaching the sensor. Typical frequencies associated with $\mathrm{AE}$ activity range from $20 \mathrm{kHz}$ to $1 \mathrm{MHz}$.

While vibration analysis on gear fault diagnosis is well established, the application of AE to this field is still in its infancy. In addition, there are limited publications on application of $\mathrm{AE}$ to gear fault diagnosis. Siores explored several AE analysis techniques in an attempt to correlate all possible failure modes of a gearbox during its useful life. Failures such as excessive backlash, shaft misalignment, tooth breakage, scuffing, and a worn tooth were seeded during tests. Siores correlated the various seeded failure modes of the gearbox with the $\mathrm{AE}$ amplitude, root mean square, standard deviation and duration. It was concluded that the AE results could be correlated to various defect conditions (Siores et al., 1997). Sentoku correlated tooth surface damage such as pitting to AE activity. An AE sensor was mounted on the gear wheel and the AE signature was transmitted from the sensor to data acquisition card across a mercury slip ring. It was concluded that $\mathrm{AE}$ amplitude and energy increased with increased pitting (Sentoku, 1998). In a separated study, Singh studied the feasibility of AE for gear fault diagnosis. In one test, a simulated pit was introduced on the pitch line of a gear tooth using an electrical discharge machining (EDM) process. An AE sensor and an accelerometer for comparative purposes were employed in both test cases. It was important to note that both the accelerometer and $\mathrm{AE}$ sensor were placed on the gearbox casing, it was observed that the $\mathrm{AE}$ amplitude increased with increased rotational speed and increased AE activity was observed with increased pitting. In a second test, periodically occurring peaks were observed when natural pitting started to appear after half an hour of operation. These AE activities increased as the pitting spread over more teeth. Singh concluded that $\mathrm{AE}$ could provide earlier detection over vibration monitoring for pitting of gears, but noted it could not be applicable to extremely high speeds or for 
unloaded gear conditions. (Singh et al., 1996) Tan offered that AE RMS (Root Mean Square) levels from the pinion were linearly correlated to pitting rates; AE showed better sensitivity than vibration at higher toque level $(220 \mathrm{Nm})$ due to fatigue gear testing using spur gears. He made sure that the linear relationship between $\mathrm{AE}$, gearbox running time and pit progression implied that the AE technique offers good potential in prognostic capabilities for monitoring the health of rotating machines. (Tan et al., 2005, 2007)

On the other hand, the signal processing method for AE signal was studied using bearing and gearbox. In the results of the research (Sheen, 2008, 2010; Yang et al., 2007), the envelope analysis was found to be useful to detect fault in rolling element bearing. The fault detection frequency of bearing can be presented in the power spectrum. Wavelet transform was used for the signal processing method for the gearboxes (Wu et al., 2006, 2009), but wavelet transforms can give the different results with the envelope analysis. It can be shown the defect frequency, but the efficiency is lower than that of envelope analysis. Thus, the signal processing method for AE signal has not been completed until now, and it must be developed in the future.

Therefore, in this paper, a signal processing method for AE signal by envelope analysis with discrete wavelet transforms is proposed. For the detection of faults generated by gear systems and a cracked rotor using the suggested signal processing, these were installed in each test rig system. In gearbox, misalignment was created by a twisted case caused by arcwelding to fix the base and bearing inner race fault was generated by severe misalignment. Through the 15 days test using AE sensor, misalignment was observed and bearing faults were also detected in the early fault stage. To identify the sensing ability of the AE, vibration signal was acquired through an accelerometer and compared with the AE signal. Also, to find the advantage of the proposed signal processing method, it was compared to traditional envelope analysis. The detection results of the test were shown by the power spectrum and comparison of the harmonics level of the rotating speed. Modal test and zooming by a microscope were performed to prove the reason of the other faults. And the crack was seeded by wire cutting with $0.5 \mathrm{~mm}$ depth. The shaft was coupled with motor and non-drive-end was left $6.5 \mathrm{~mm}$ by lifting tool. During rotating the shaft, AE signals were acquired by $\mathrm{AE}$ sensor with $5 \mathrm{MHz}$ sampling frequency and 0.5 seconds storing time. The AE signals were transformed by FFT to create the power spectrums, and in the spectrums several peaks were occurred by the crack growth. Along the growth of the crack, the characteristic of the power spectrum was changed and displayed different frequencies.

\section{Signal processing method}

Envelope analysis typically refers to the following sequence of procedure: (1) band-pass filtering (BPF), (2) wave rectification, (3) Hilbert transform or low-pass filtering (LPF) and (4) power spectrum. The purpose of the band-pass filtering is to reject the low-frequency high-amplitude signals associated with the ith mechanical vibration components and to eliminate random noise outside the pass-band. Theoretically, in HFRT (High Frequency Resonance Technique) analysis, the best band-pass range includes the resonance of the bearing components. This frequency can be found through impact tests or theoretical calculations involving the dimensions and material properties of the bearing. However, it is very difficult to predict or specify which resonant modes of neighboring structures will be 
excited. It will be costly and unrealistic in practice to find the resonant modes through experiments on rotating machinery that may also alter under the different operational conditions. In addition, it is also difficult to estimate how these resonant modes are affected in the assembly of a complete bearing and mounting in a specific housing, even if the resonant frequencies of individual bearing elements can be tested or calculated theoretically (Misiti et al., 2009). Therefore, most researchers decide on the band-pass range as on option. To recover the disadvantage of this option, wavelet analysis is included in the process of traditional envelope analysis in this paper.

Wavelet theory (Burrus et al., 1997) is introduced that is a tool for the analysis of transient, non-stationary, or time-varying phenomena. Wavelet analysis is also called wavelet transform. There are two kinds of wavelet transform: continuous wavelet transform (CWT) and discrete wavelet transform (DWT). CWT is defined as the sum over all time of the signal multiplied by scaled, shifted versions of the wavelet function. To use CWT, one signal can be decomposed into a series of "small" waves belonging to a wavelet family. The wavelet family is composed of scaling functions, $\phi(t)$ deduced by father wavelet and wavelet functions, $\psi(t)$ deduced by mother wavelet. The scaling function can be represented by the following mathematical expression:

$$
\phi_{j, k}(k)=2^{j / 2} \phi\left(2^{j} t-k\right)
$$

where $j$ represents the scale coefficient and $k$ represents shift coefficient. Scaling a wavelet simply means stretching (or compressing) it. Shifting a wavelet simply means delaying (or hastening) its onset. Mathematically, delaying a function $f(t)$ by $k$ is represented by $f(t+k)$. Similarly, the associated wavelet function can be generated using the same coefficients as the scaling function.

$$
\psi_{j, k}(t)=2^{j / 2} \psi\left(2^{j} t-k\right)
$$

The scaling functions are orthogonal to each other as well as the wavelet functions as shown in the following equations:

$$
\begin{aligned}
& \int_{-\infty}^{\infty} \phi(2 t-k) \cdot \phi(2 t-l) d t=0 \text { for all } k \neq l \\
& \int_{-\infty}^{\infty} \psi(t) \cdot \phi(t) d t=0
\end{aligned}
$$

Using an iterative method, the scaling function and associated wavelet function can be computed if the coefficients $j$ and $k$ are known.

For many signals, the low-frequency content is the most important part. It is what gives the signal its identity. The high-frequency content, on the other hand, imparts flavour or nuance that is often useful for singular signal detection. In wavelet analysis, we often speak of approximations and details. The approximations are the high-scale, low frequency components of the signal. The details are the low-scale, high-frequency components. A signal can be decomposed into approximate coefficients $a_{j, k}$, through the inner product of the original signal at scale $j$ and the scaling function.

$$
\alpha_{j, k}=\int_{-\infty}^{\infty} f_{j}(t) \cdot \phi_{j, k}(t) d t
$$


Similarly the detail coefficients $d_{j, k}$ can be obtained through the inner product of the signal and the complex conjugate of the wavelet function.

$$
d_{j, k}=\int_{-\infty}^{\infty} f_{j}(t) \cdot \psi_{j, k}(t) d t
$$

However, CWT takes a long time due to calculating the wavelet coefficient at all scales and it produces a lot of data. To overcome such a disadvantage, we can choose scales and positions based on powers of two - the so-called dyadic scales and positions - then wavelet analysis will be much more efficient and just as accurate. Such an analysis is obtained from the discrete wavelet transform (DWT). The approximate coefficients and detail coefficients decomposed from a discredited signal can be expressed as

$$
\begin{aligned}
& \alpha_{(j+1), k}=\sum_{k=0}^{N} \alpha_{j, k} \int \phi_{j, k}(t) \cdot \phi_{(j+1), k}(t) d t=\sum_{k} \alpha_{j, k} \cdot g[k] \\
& \alpha_{(j+1), k}=\sum_{k=0}^{N} \alpha_{j, k} \int \phi_{j, k}(t) \cdot \psi_{(j+1), k}(t) d t=\sum_{k} \alpha_{j, k} \cdot h[k]
\end{aligned}
$$

The decomposition coefficients can therefore be determined through convolution and implemented by using a filter. The filter, $g[k]$, is a low-pass filter and $h[k]$ is a high-pass filter. The decomposition process can be iterated, with successive approximations being decomposed in turn, so that one signal is broken down into many lower resolution components. This is called the wavelet decomposition tree as shown in Fig. 1.

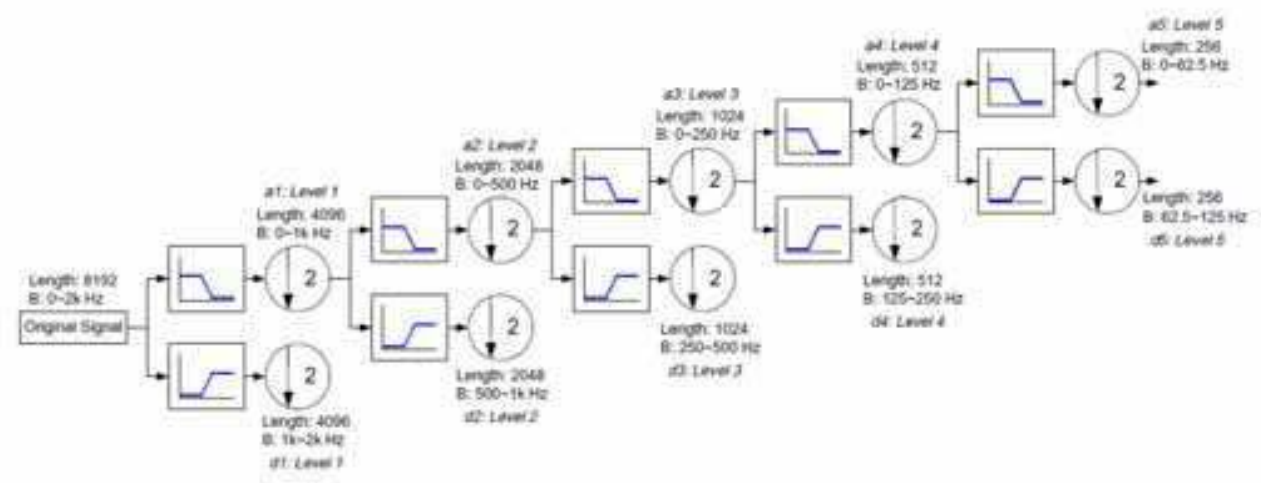

Fig. 1. Wavelet decomposition tree

DWT has a de-noise function and a filter effect focused on impact signal. To make up the weak point of BPF of the envelope analysis, DWT was intercalated on typical envelope analysis, between BPF and wave rectification exactly. The signal by DWT will be separated to different band widths by decomposition level and adapted to the signal with impact.

For more complicated signals which are expressible as a sum of many sinusoids, a filter can be constructed which shifts each sinusoidal component by a quarter cycle. This is called a Hilbert transform filter. Let $H_{t}\{x\}$ denotes the output at time $t$ of the Hilbert-transform filter applied to the signal $x$. Ideally, this filter has magnitude 1 at all frequencies and introduces a phase shift of $-\pi / 2$ at each positive frequency and $+\pi / 2$ at each negative frequency. When a 
real signal $x(t)$ and its Hilbert transform $y(t)=H_{t}\{t\}$ are used to form a new complex signal $z(t)=x(t)+j y(t)$, the signal $z(t)$ is the (complex) analytic signal corresponding to the real signal $x(t)$. In other words, for any real signal $x(t)$, the corresponding analytic signal $z(t)=$ $x(t)+j H_{t}\{x\}$ has the property that all 'negative frequencies' of $x(t)$ have been 'filtered out' (Douglas \& Pillay, 2005). Hence, the coefficients of complex term in the corresponding analytic signal were used for FFT.

Fig. 2 shows an analytic signal of the Hilbert transform for envelope analysis. The solid line is a time signal and the dash is its envelope curve. A high frequency signal modified by wavelet transform is modulated to a low frequency signal with no loss of the fault information due to envelope effect. According to that, the fault signals in the low frequency region can be detected using the analytic signal. That is an important fact for the proposed signal processing method. Therefore, the proposed signal processing method in this paper is an envelope analysis with DWT and using the coefficients of the complex term in Hilbert transform.

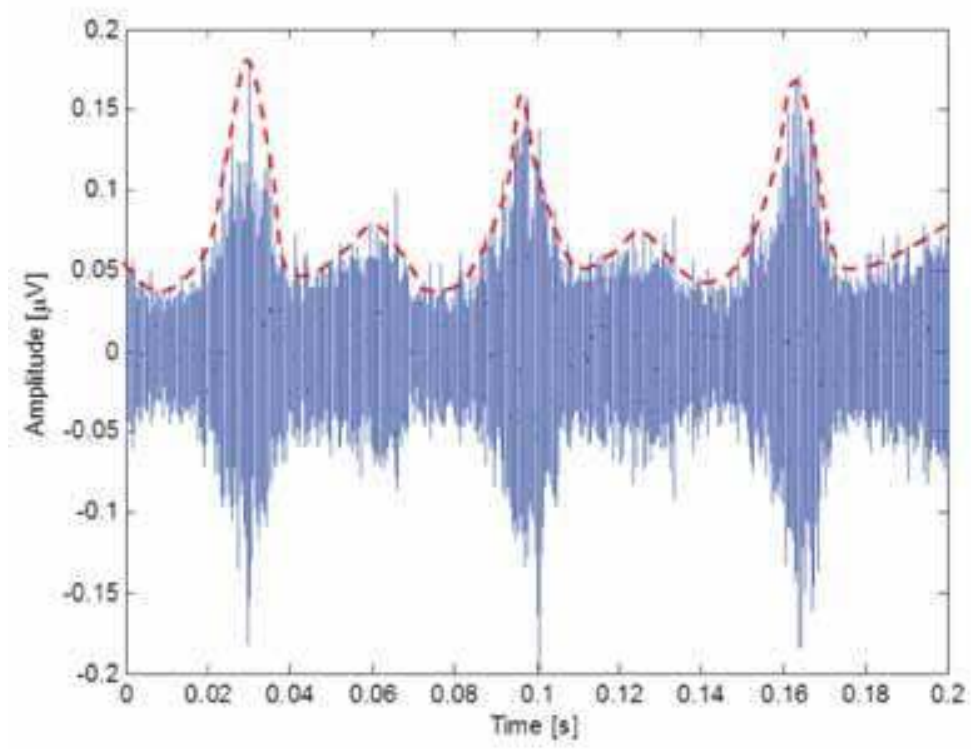

Fig. 2. Analytic signal (dash) of the envelope effect

Furthermore, to reduce the noise level in the power spectrum, the spectrum values were presented as the mean value of each day. Fig. 3 shows the power spectrums of the two different signal processing method. Fig. 3(a) is from envelope analysis, and Fig. 3(b) shows the envelope analysis intercalated DWT using Daubechies mother function between BPF and wave rectification. In Fig. 3, the DWT has an effect the amplifying sidebands peaks, especially about gear mesh frequencies, so the peaks of the harmonics of the rotating speed $\left(f_{r}\right)$ and gear mesh frequencies $\left(f_{m}\right)$ are bigger than another, and we can check up them easily. Therefore, in the following result, the power spectrum through envelope analysis with DWT will be shown. 


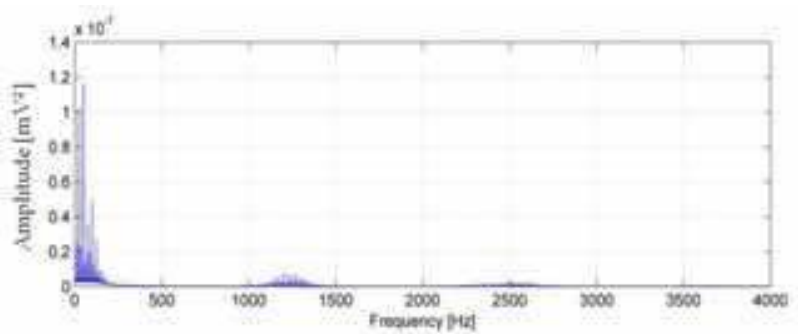

(a) Envelope analysis

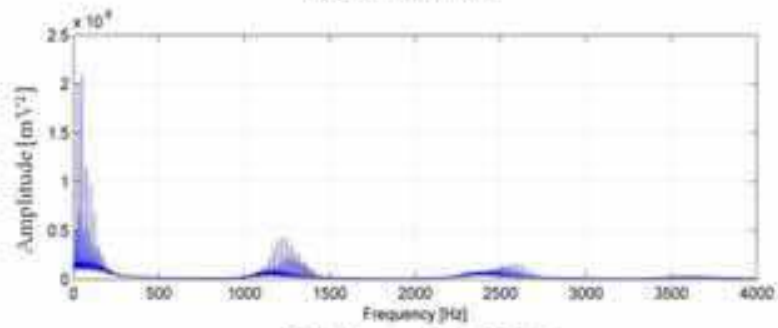

(b) Envelope analysis with DWT

Fig. 3. The comparison of Power spectrums in Envelope analysis with/ without DWT

\section{Gearbox}

\subsection{Test-rig}

The test-rig employed for this investigation consists of one identical oil-bath lubricated gearbox, 3 HP-motor, rigid coupling, tapper-roller bearing, pinion, gear, control panel and break system, as seen Fig. 4. The pinion was made from steel with heat treatment, the number of teeth is 70, and diameter is $140 \mathrm{~mm}$. The gear was made from steel, but it was produced without any heat treatment process during manufacturing. The number of gear teeth is 50 and diameter is $100 \mathrm{~mm}$, and module is $2 \mathrm{~mm}$ for the gear and pinion, respectively.

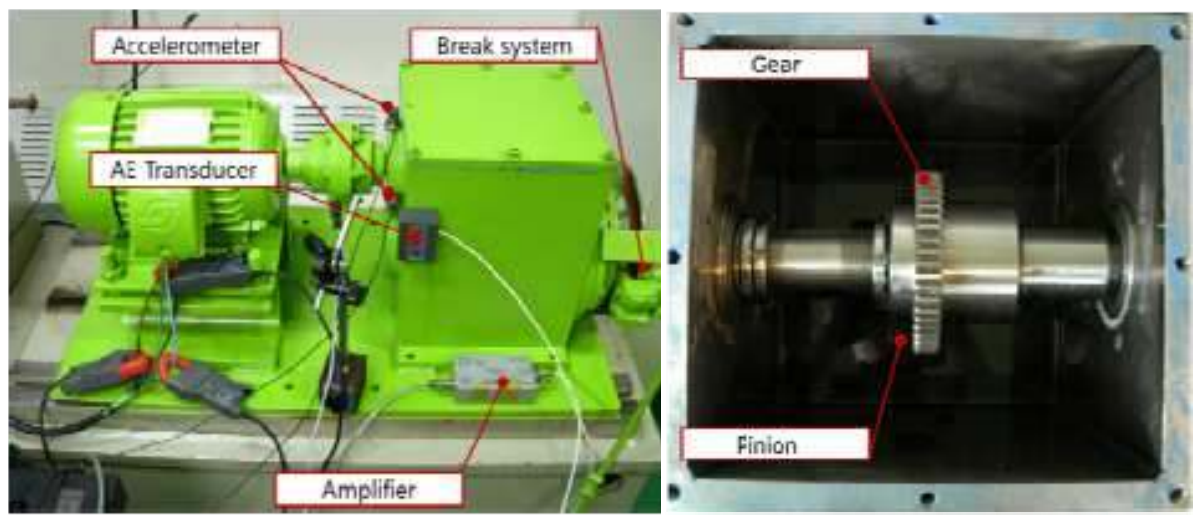

Fig. 4. Test-rig 
A simple mechanism that permitted a break of disk-pad type to be rotated relative to each other was employed to apply torque to the gear. Contact ratio (Pinion/ Gear) of the gears was 1.4. The motor used to drive the gearbox was a 3-phase induction motor with a maximum running speed of $1800 \mathrm{rpm}$ respectively and was operated for 15 days with $1500 \mathrm{rpm}$. The torque on the output shaft was $1.2 \mathrm{kN} \cdot \mathrm{m}$ while the motor was in operation, and other specifications of the gearbox are given as in Table 1.

\begin{tabular}{|c|c|c|c|c|}
\hline & \multicolumn{2}{|c|}{ Gear } & \multicolumn{2}{|c|}{ Pinion } \\
\hline No. of teeth & \multicolumn{2}{|c|}{50} & \multicolumn{2}{|c|}{70} \\
\hline $\begin{array}{c}\text { Speed of } \\
\text { shaft }\end{array}$ & \multicolumn{4}{|c|}{$25.01 \mathrm{rev} / \mathrm{s}$} \\
\hline $\begin{array}{l}\text { Meshing } \\
\text { frequency }\end{array}$ & \multicolumn{2}{|c|}{$1250 \mathrm{~Hz}$} & \multicolumn{2}{|c|}{$1750 \mathrm{~Hz}$} \\
\hline \multicolumn{5}{|c|}{ Bearing (NSK HR 32206J) } \\
\hline $\begin{array}{l}\text { No. of } \\
\text { rolling } \\
\text { element }\end{array}$ & 17 & Type & $\begin{array}{l}\text { Defect Freq. } \\
\qquad\left(f_{d}\right)\end{array}$ & $\begin{array}{l}\text { Fault Freq. } \\
\qquad\left(f_{d} \mathbf{X} f_{r}\right)\end{array}$ \\
\hline $\begin{array}{c}\text { Diameter of } \\
\text { outer race }\end{array}$ & $62 \mathrm{~mm}$ & \multirow[b]{2}{*}{$\begin{array}{c}\text { BPFO } \\
\text { BPFI } \\
\text { FTF } \\
\text { BSF }\end{array}$} & \multirow[b]{2}{*}{$\begin{array}{l}8.76 \mathrm{~Hz} \\
11.24 \mathrm{~Hz} \\
3.84 \mathrm{~Hz} \\
0.44 \mathrm{~Hz}\end{array}$} & \multirow[b]{2}{*}{$\begin{array}{l}219.3 \mathrm{~Hz} \\
281.38 \mathrm{~Hz} \\
96.13 \mathrm{~Hz} \\
11.01 \mathrm{~Hz}\end{array}$} \\
\hline $\begin{array}{c}\text { Diameter of } \\
\text { inner race }\end{array}$ & $30 \mathrm{~mm}$ & & & \\
\hline \multicolumn{5}{|c|}{$\begin{array}{l}\text { BPFO : ball pass frequency of outer race } \\
\text { BPFI : ball pass frequency of inner race } \\
\text { FTF : fundamental train frequency } \\
\text { BSF : ball spin frequency }\end{array}$} \\
\hline
\end{tabular}

Table 1. Specification of gearbox and bearing

\subsection{Acquisition system and test procedures}

AE sensors used in this paper are a broadband type with a relative flat response in the range frequency from $10 \mathrm{kHz}$ to $1 \mathrm{MHz}$. They are placed on the right side of the gearbox cases near the coupling in the horizontal direction at the same height with the shaft center (Fig. 4).

AE signals are pre-amplified by $60 \mathrm{~dB}$ and the output from the amplifier is collected by a commercial data acquisition card with $10 \mathrm{MHz}$ sampling rate during the test. Prior to the analog-to-digital converter (ADC), anti-aliasing filter is employed that can be controlled DAQ software. And Table 2 is shown the detail specifications of the data acquisition system. Before the test, attenuation test on the gearbox components was taken in order to understand the characteristics of the test-rig. The gearbox was run for 30 minutes prior to acquiring $\mathrm{AE}$ data for the unload condition. Based on the sampling rate of $10 \mathrm{MHz}$, the available recording acquisition time was $2 \mathrm{sec}$. 


\begin{tabular}{|c|l|}
\hline $\begin{array}{c}2 \text { Channel } \\
\text { AE } \\
\text { system on } \\
\text { PCI-Board }\end{array}$ & $\begin{array}{l}\text { 18-bit A/ D conversion } \\
\text { (oM samples/ s rate } \\
\text { (on one channel, 5M samples/ s on } 2 \mathrm{AE} \text { channels) }\end{array}$ \\
\hline $\begin{array}{c}\text { AE Sensor } \\
\text { (Wideband } \\
\text { type) }\end{array}$ & $\begin{array}{l}\text { Peak sensitivity }[\mathrm{V} / \mu \mathrm{bar}]:-62 \mathrm{~dB} \\
\text { Operating frequency range }: 100-1,000 \mathrm{kHz} \\
\text { Resonant freq. [V/ } \mu \mathrm{bar}]: 650 \mathrm{kHz} \\
\text { Directionality }: \pm 1.5 \mathrm{~dB}\end{array}$ \\
\hline $\begin{array}{c}\text { Preamplifier } \\
\text { Gain }\end{array}$ & $\begin{array}{l}\text { Wide dynamic range }<90 \mathrm{~dB} \\
\text { Single pow er/ signal BNC or optional separate pow er/ signal BNC } \\
20 / 40 / 60 \mathrm{~dB} \text { selectable gain }\end{array}$ \\
\hline
\end{tabular}

Table 2. Specifications of data acquisition system

\subsection{Experiment result and discussion}

In general, the misaligned gear which almost always excites higher order $f_{m}$ harmonics is shown as in Fig. 5. Often, only small amplitudes will be at the fundamental $f_{m}$, but much higher levels will be at $2 f_{m}$ and/ or $3 f_{m}$. The sideband spacing about $f_{m}$ might be $2 f_{r}$ or even $3 f_{r}$ when gear misalignment problems are involved. When significant tooth wear occurs, not only will sidebands appear about $f_{m}$, but also about the gear natural frequencies. In the case of those around $f_{m}$, the amplitude of the sidebands themselves is a better indicator for wear than the amplitude of $f_{m}$.

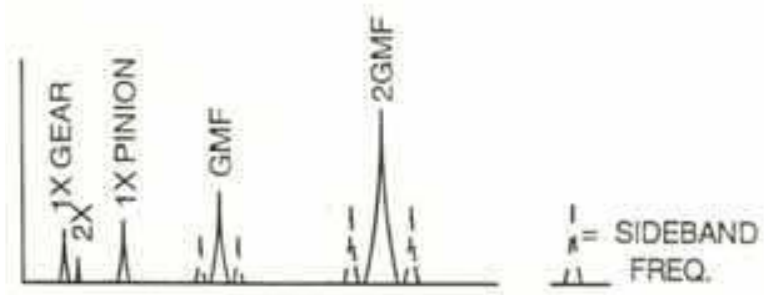

Fig. 5. Spectrum indicating misalignment of gear

As for significant gear eccentricity and/ or backlash, these problems display the following characteristics:

- Both eccentricity and backlash excite the gear natural frequencies as well as $f_{m}$. They also may generate a number of sidebands about both the natural and gear mesh frequencies.

- If a gear is eccentric; it will modulate the natural frequency and gear mesh frequencies, both of which will be sidebanded around the $f_{r}$ of the eccentric gear. An eccentric gear can generate significant forces, stresses and vibration if it is forced to bottom out with the meshing gears. (James \& Bery, 1994)

In the results of the envelop analysis with DWT, the high harmonics of $f_{m}$ occurred by strong wearing phenomena caused by misaligned teeth. In the power spectrum (Fig. 6), $25 \mathrm{~Hz}\left(f_{r}\right)$ and its harmonics are generated and $11.32 \mathrm{~Hz}$ was the ball pass frequency of inner race (BPFI $\left.\left[f_{d}\right]\right)$. In Fig. 6(c) and (d), the center dash line is shown for $f_{m}$ and $2 f_{m}$, and their side lines are the sidebands with difference $25 \mathrm{~Hz}\left(f_{r}\right)$. 

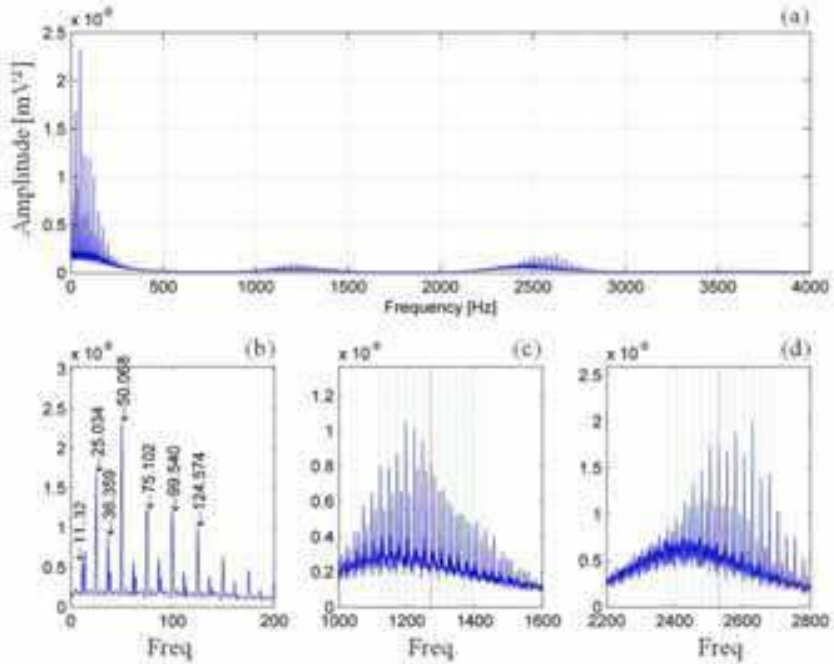

Fig. 6. Power spectrum of the second day

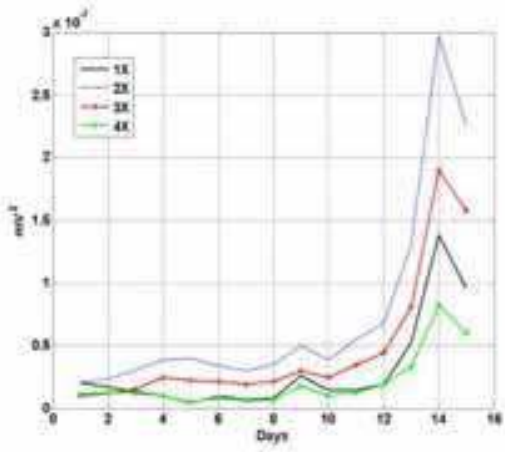

(a) Harmonics of $f_{r}$

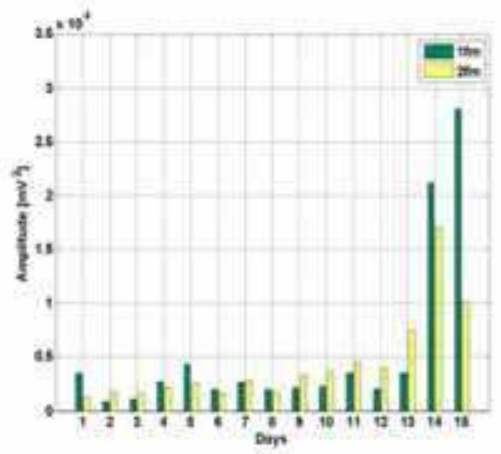

(b) Harmonics of $f_{m}$

Fig. 7. Peak level trend among days
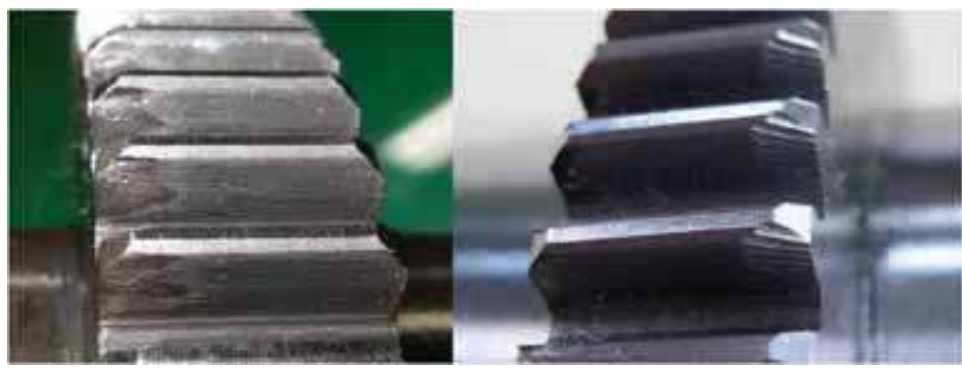

Fig. 8. Gear tooth weaned by misalignment 


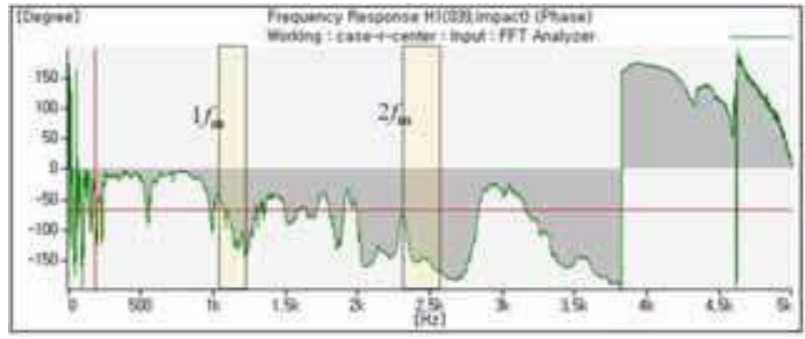

(a) Phase

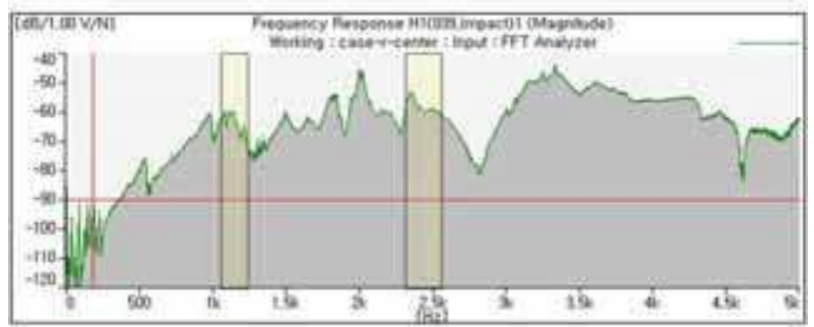

(b) Frequency response function

Fig. 9. Modal test result

In condition monitoring for general rotating machinery, the harmonics $\left(2 f_{r}, 3 f_{r}, 4 f_{r} \ldots\right)$ of $f_{r}$ are occurred higher than $f_{r}$ when the misalignment was happened. According to the phenomena of misalignment as shown in Fig.5, high level harmonics of $f_{r}$ were generated such as in Fig. 6(b), and $2 f_{r}$ was always bigger than $f_{r}$ as shown in Fig. 7(a). The level of $2 f_{m}$ from second to thirteenth day was higher than or similar to $f_{r}$ as shown in Fig. 7(b). Thus, it is easily catching up to the misalignment that occurred in this test rig. However, it might be that faults of this system are not only misalignment but also resonance trouble, looseness, bearing fault, etc.

Wearing effect by misalignment pollutes the lubrication oil. In Fig. 8, it could be found by the worn teeth and the spots near the pieces of gear teeth. The dripped pieces from the unloading surface raised the wearing effect on the loading surface, and then the gap between gear and pinion was increased. In addition, we could know that the impact marks on the unloading surface (Fig. 8(b)) were generated by misalignment; the impacting force was strong in the initial condition. In this way, the gear teeth were seriously damaged as in Fi g. 8. In Fig. 6(c) and (d), the sidebands are created on wide-spread frequency range near $f_{m}$ and $2 f_{m}$. That is similar to a state excited by impact force. To confirm the natural frequencies of the test-rig, modal test was fulfilled. The result of the modal test as in Fig. 9 show that $f_{m}$ and $2 f_{m}$ exist on the exiting frequency range. On the other hand, partial frequency bands close to $f_{m}$ and $2 f_{m}$ were excited by the impact force, but it is not an exact natural frequency because the phase did not shift enough. Therefore, the peaks near $f_{m}$ and $2 f_{m}$ were amplified and have many sidebands of $f_{r}$ and $11.32 \mathrm{~Hz}$ (BPFI $\left[f_{d}\right]$ ). Therefore, it is considered that excessive backlash occurred. Moreover, Fig. 10(a) shows the zooming power spectrum of Fig. 6(a) focused on $f_{r}$ harmonics. We could clearly know that if the sidebands were caused by BPFI $\left[f_{d}\right]$, then the inner race had some kind of fault. To find out the fault, the surface of the bearing inner race was carried out and viewed by a microscope with $100 \mathrm{X}$ zoom as shown in Fig. 11. Small spots were found on the surface, and small cracks were found out on 
the spots. However, this trouble was not seeded and existed from the initial condition. Thus, it is as assumed that the problem happened in assembly and/ or was caused by misalignment.

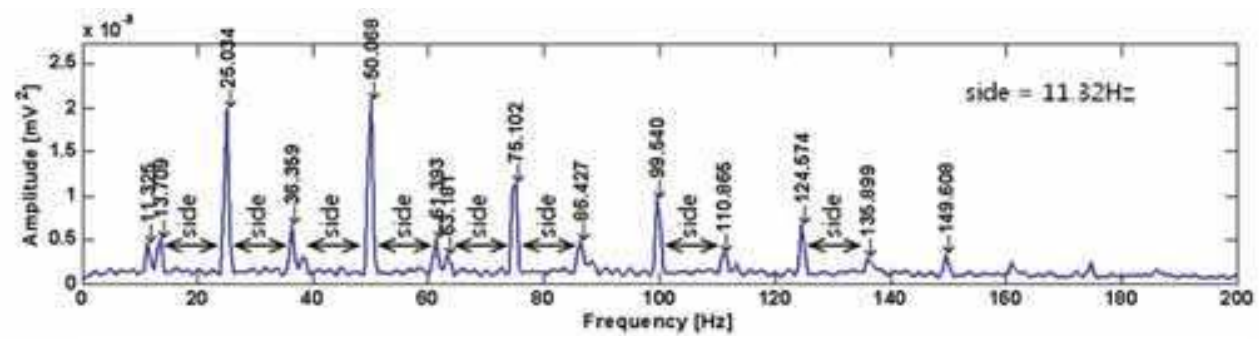

(a) Power spectrum of the AE signal using envelope analysis with DWT(suggested)

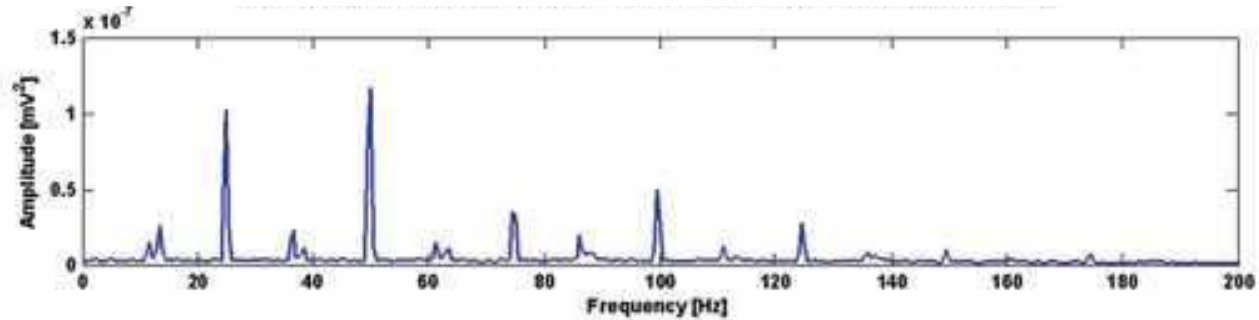

(b) Power spectrum of the AE signal using traditional envelope analysis

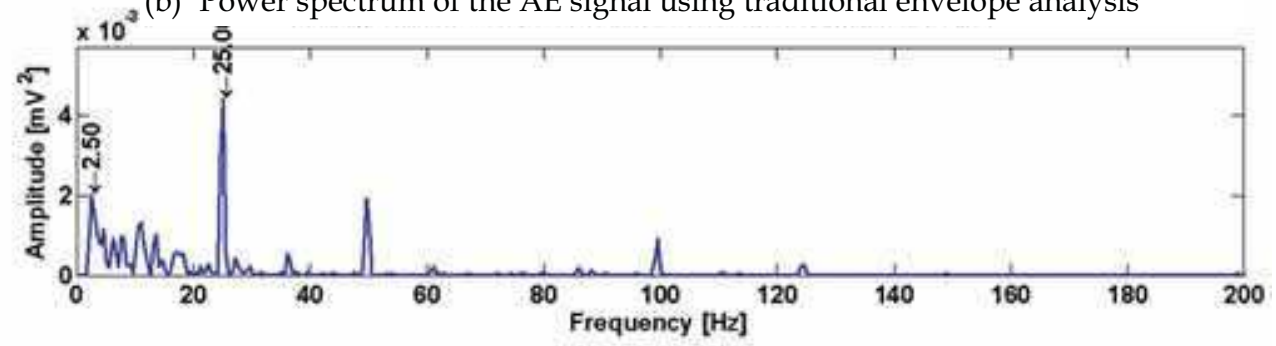

(c) Power spectrum of the signal from accelerometer

Fig. 10. Sidebands BPFI in the first day power spectrum

To identify the sensing ability of the AE, vibration signal was acquired through accelerometer and compared with the AE signal. Also, to find the advantage of the proposed signal processing method, it was compared to traditional envelope analysis.

The power spectrum of the AE signal using traditional envelope analysis is shown in Fig. 10(b), and the power spectrum using the vibration signal by accelerometer is displayed on Fig. 10(c). The vibration signal was treated by the same method with AE signal. The harmonics of $f_{r}$ are generated, and $2 f_{r}$ for detecting the misalignment is created and can be found in all spectrums (Fig. 10) but the power spectrum of the AE signal, Fig. 10(a) and (b), can explicitly display the defect frequencies as compared to the accelerometer signal (Fig. 10(c)). For example, in Fig. 10(c), the sidebands of BPFI are not easily found because of the higher level of noise in the low frequency range below $f_{r}$ than in the AE signal with or without DWT. 

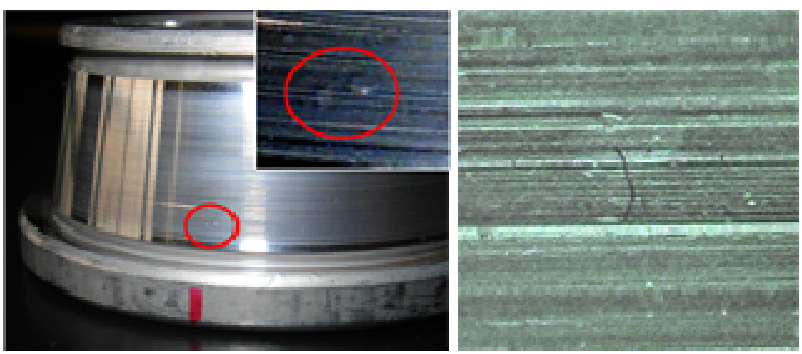

Fig. 11. Zooming of the inner race surface of the fault bearing

\begin{tabular}{|c|c|c|c|}
\hline \multicolumn{2}{|c|}{ Frequency [Hz] } & Traditional Method & Proposed method \\
\hline 13.709 & $1 \mathrm{X}-\mathrm{BPFI}$ & 0.2146 & 0.2459 \\
\hline 25.034 & $1 \mathrm{X}$ & 0.8727 & 0.9525 \\
\hline 36.360 & $1 \mathrm{X}+\mathrm{BPFI}$ & 0.1936 & 0.3196 \\
\hline 38.750 & $2 \mathrm{X}-\mathrm{BPFI}$ & 0.0952 & 0.1435 \\
\hline 50.070 & $2 \mathrm{X}$ & 1.0000 & 1.0000 \\
\hline 61.393 & $2 \mathrm{X}+\mathrm{BPFI}$ & 0.1277 & 0.2470 \\
\hline 63.181 & $3 \mathrm{X}-\mathrm{BPFI}$ & 0.0970 & 0.1560 \\
\hline 75.102 & $3 \mathrm{X}$ & 0.3044 & 0.5465 \\
\hline 86.427 & $3 \mathrm{X}+\mathrm{BPFI}$ & 0.1699 & 0.2352 \\
\hline 99.540 & $4 \mathrm{X}$ & 0.4269 & 0.4616 \\
\hline 110.866 & $4 \mathrm{X}+\mathrm{BPFI}$ & 0.1062 & 0.1675 \\
\hline 124.574 & $5 \mathrm{X}$ & 0.2312 & 0.3253 \\
\hline 135.899 & $5 \mathrm{X}+\mathrm{BPFI}$ & 0.0714 & 0.1443 \\
\hline
\end{tabular}

Table 3. Ratio of peaks versus the maximum peak in respective spectrum

According to the above results, we can understand that the $\mathrm{AE}$ signal can detect the fault more easily than accelerometers and can be used in the condition monitoring system for early detection fault. Moreover, as shown in Table 3 which is the ratio of peaks versus the maximum peak in the respective spectrum, the peak levels of the harmonics of $f_{r}$ and sidebands caused by BPFI are highly generated in the proposed signal processing method (Fig. 10(a)) than the traditional method. This can lead good feature values to evaluate the condition of the machinery. Therefore, the power spectrum of the proposed envelope analysis using $\mathrm{AE}$ signal can be shown the clean result with harmonics and sidebands and is a better technique for condition monitoring system.

\section{Cracked rotor}

\subsection{Experiment system}

Test rig consisted of a motor, a flexible coupling, rolling element bearings (NSK6200), three steel bearing housings, a lifting tool and a cracked shaft. The transverse crack was seeded by 
wire-cutting with $0.5 \mathrm{~mm}$ depth on the shaft made from SM45C. As shown in Fig. 12, the crack was positioned at $5 \mathrm{~mm}$ near to the second drive-end bearing, and the non-driven end of the shaft was left $6.5 \mathrm{~mm}$ with bearing housing by the lifting tool.

$\mathrm{AE}$ signal was acquired by an $\mathrm{AE}$ sensor and transferred to amplifier, analog-filter, DAQ board and HDD of a desktop. AE sensor is a wideband type with a relative flat response in the range frequency range from $100 \mathrm{kHz}$ to $1 \mathrm{MHz}$. AE signals were pre-amplified with $60 \mathrm{~dB}$ and the output from the amplifier was collected by a commercial data acquisition card with $5 \mathrm{MHz}$ sampling rate during the test. The signals were stored $0.5 \mathrm{sec}$ by every $30 \mathrm{sec}$ until the shaft was fractured, and the rotating speed of the motor was 600rpm $(10 \mathrm{~Hz})$.

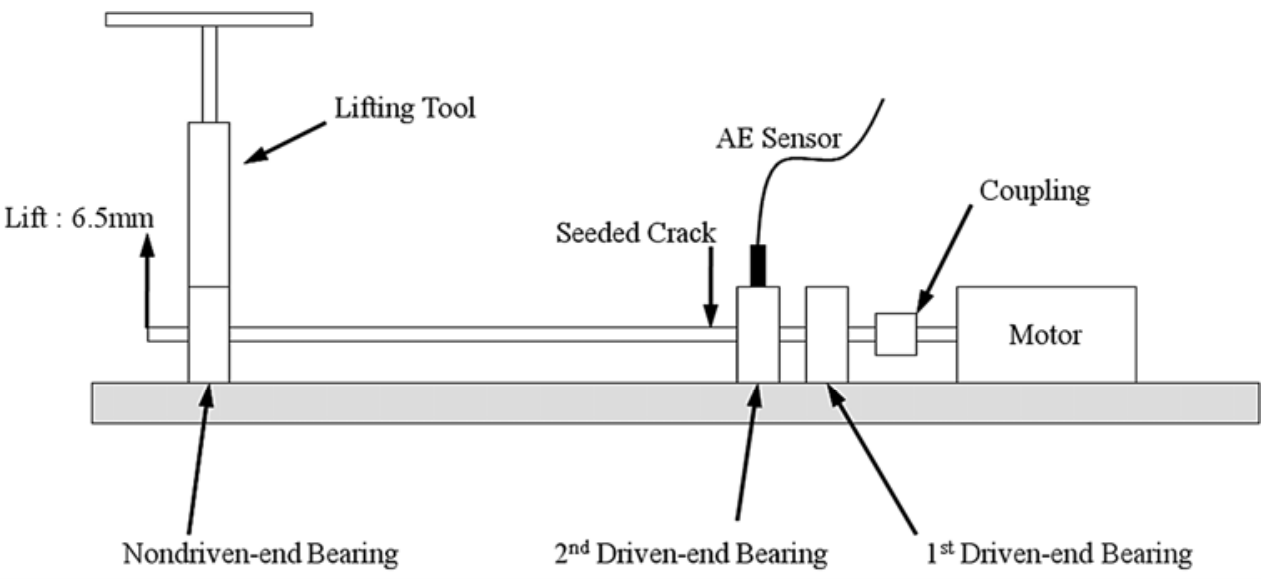

Fig. 12. Experiment system

\subsection{Test result and discussion}

The operating speed was $600 \mathrm{rpm}$, and the initial radial load for $160 \mathrm{~N}$ was employed. The radial load was a variable parameter because it was applied by keeping the lifting distance with $6.5 \mathrm{~mm}$ of the non-drive end of the shaft, and the test terminated on a fracture of the shaft. Fig. 13 shows the observations of continuous feature values as mean value, RMS, peak value and entropy estimation. In information theory, uncertainty can be measured by entropy. The entropy of a distribution is the amount of a randomness of that distribution. Entropy estimation is two stage processes; first a histogram is estimated and thereafter the entropy is calculated. Here, we estimate the entropy of AE signal with using unbiased estimated approach. Fig. 13(a), relatively high level of AE activity was noted from 18 minutes, and it was increased until 60 minutes. But in RMS, Peak and Entropy estimation, the levels were kept to 18 minutes beside a peak in around 9 minutes, since that these were continuously decreased to 70 minutes and were increased with hunting with several minute intervals until the fracture.

Interestingly observations of the $\mathrm{AE}$ waveform, sampled at $5 \mathrm{MHz}$ showed changing characteristics as a function of time. Fig. 14 shows a contour map of the peaks level of each frequency with time. Rotating speed $(9.5 \mathrm{~Hz})$ and 3rd harmonic of rotating speed $(28.6 \mathrm{~Hz}$, 3X) dominated while the test as shown in Fig. 14(b). It is normally known that $3 \mathrm{X}$ is caused by misalignment of the bearings created by the loading system for this test (Hatch \& Bently, 
2002). However, the harmonic component (3X) was kept the level in the wavelet level 6(Fig. 14(b)), but it was increased from 30 minutes in the wavelet level 4(Fig. 14(a)). Additionally, 1X started increasing earlier than $3 \mathrm{X}$ as shown in Fig. 14(a).

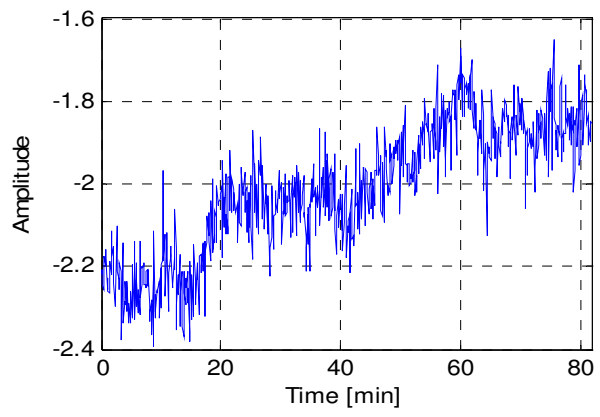

(a) Mean value $\left[\mu V X 10^{-4}\right]$

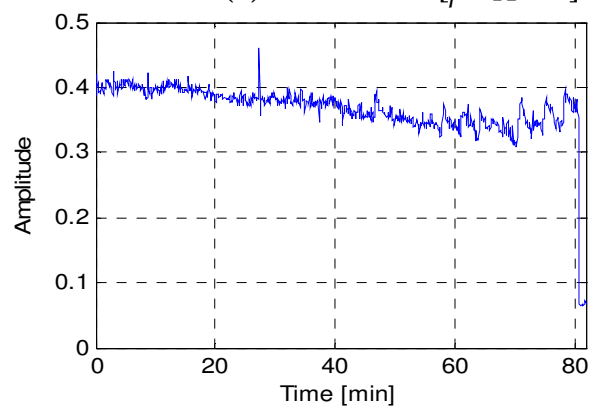

(c) Peak value $[\mu V]$

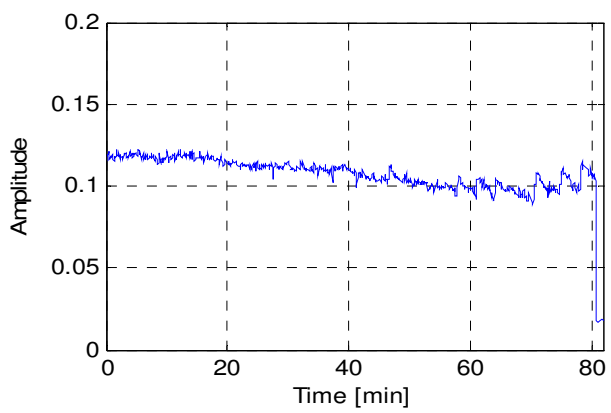

(b) RMS value $[\mu \mathrm{V}]$

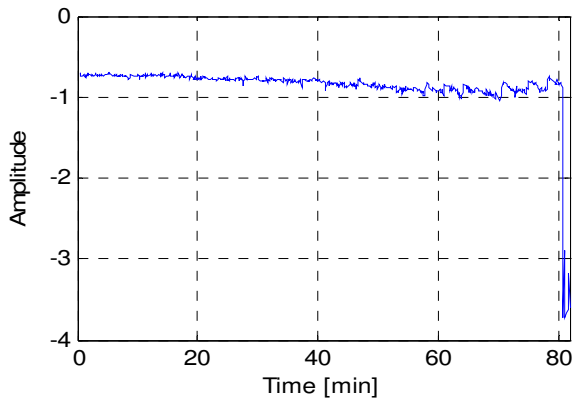

(d) Entropy estimation value

Fig. 13. Shaft test results; run-to-failure

$31 \mathrm{~Hz}$ and $62 \mathrm{~Hz}$ that were the harmonics of the fundamental train frequency (FTF or cage noise) of the bearing were continuously occurred. Cage noise can be generated in any type of bearing and the magnitude of it is usually not very high. Characteristics of this noise include: (1) it occurs with pressed steel cages, machined cages and plastic cages. (2) It occurs with grease and oil lubrication. (3) It tends to occur if a moment load is applied to the outer ring of a bearing. (4) It tends to occur more often with greater radial clearance. In Fig. 14, $62 \mathrm{~Hz}$ was continuously detected; $31 \mathrm{~Hz}$ was detected with $3 \mathrm{X}$. In a general bearing system, the amplitude of the bearing fault frequency is depended on the load grade and is increased along the growing load grade. How ever, $31 \mathrm{~Hz}$ of the case noise of this test was not followed the load scale because loading force for this test was decreased with the crack growth. So, it was shown that $31 \mathrm{~Hz}$ was related with the crack growth.

According to this result, we could know that the reason of $3 \mathrm{X}(28.6 \mathrm{~Hz})$ was the moment load by the loading system; $31 \mathrm{~Hz}$ was connected with the crack growth. Therefore, the peak levels around $3 \mathrm{X}$ and $31 \mathrm{~Hz}$ was excited by the two frequencies and was increased with the crack growth.

To clear more the characteristic of the crack growth, in addition, PAC energy value was observed. In acoustic emission technology, PAC-Energy is a 2-byte parameter derived from the integral of the rectified voltage signal over the duration of the $\mathrm{AE}$ hit (or waveform), 
hence the voltage-time units $\left(\mu \mathrm{V}^{2}\right.$. sec). So, PAC energy value was determined by an integral of the square sum total of the transferred time signal in each wavelet level. Fig. 15 shown the energy level of every wavelet levels along time, and its value was transferred to logarithmic value because of too low resolution in linear scale.

Fig. 15 shows the energy trend of wavelet level 1 to 8 . Many peaks were created while the test in wavelet level 1(Fig. 15(a)), a high peak was created around 9 minutes existed in wavelet level 1 to 4 . Wavelet level 2, 4, 5 and 6 shows a similar trend after 10minutes. The energy level was slowly increased with time until about 30 minutes, and then it was increased fast until 35 minutes (additionally, it was considered that this increasing was related with the growth of the $3 \mathrm{X}$ and $31 \mathrm{~Hz}$ in Fig. 14(a)), after that it was decreased a little for 10 minutes. And it was hunted with every several minutes about 4 minutes until close fracture. In this trend, we had considered of two phenomena, the high peak and the period hunting.

We could mind that the high peak was related with initial crack growth. Because it was shown as follows,

- The increasing ratio of the energy was changed after it was happened.

- The mean value was began fast change (Fig. 13(a)).

- $\quad$ Generated in high frequency range (Fig. 15(a) (d)).

The period hunting was clearly occurred and displayed in wavelet level $2,4 \sim 8$. It was considered that it could indicate a state of the final stage of the fracture in the rotating shaft because of follows,

- It had a period about 4 minutes.

- It was displayed in lower frequency range than the high peak (Fig. 15(e) (h)).

- Its level was increased along near to the fracture.

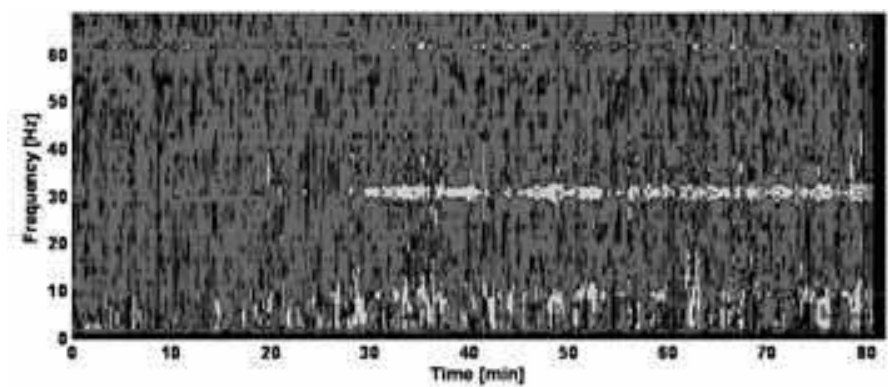

(a) Wavelet level 4

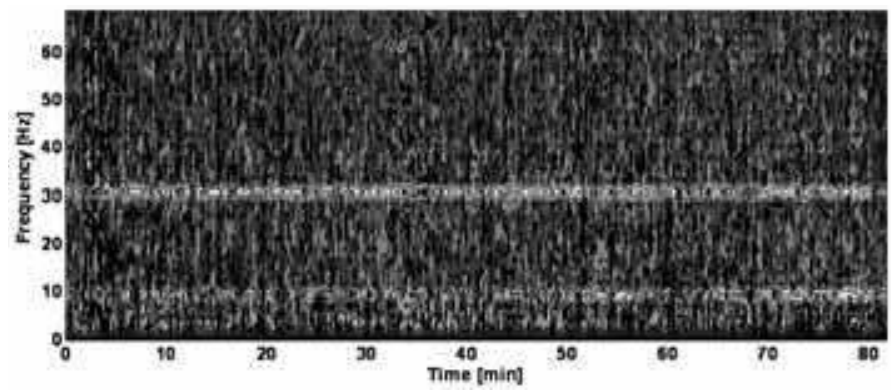

(b) Wavelet level 6

Fig. 14. Peak level trend by frequency 


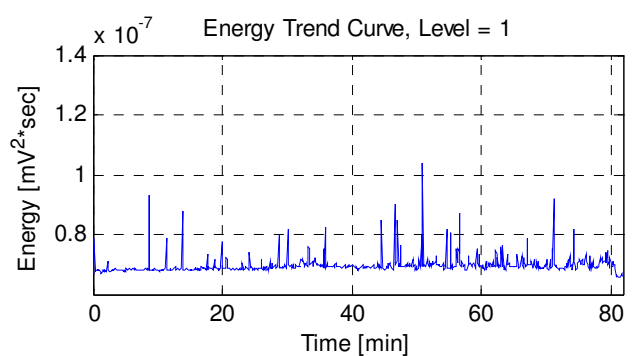

(a) Level 1

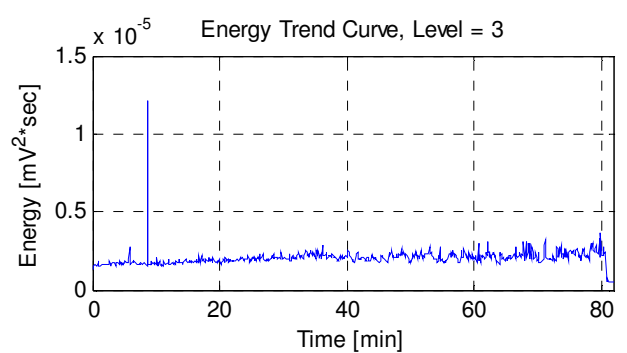

(c) Level 3

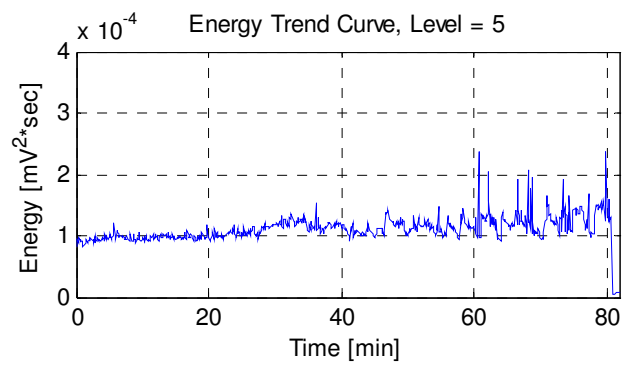

(e) Level 5

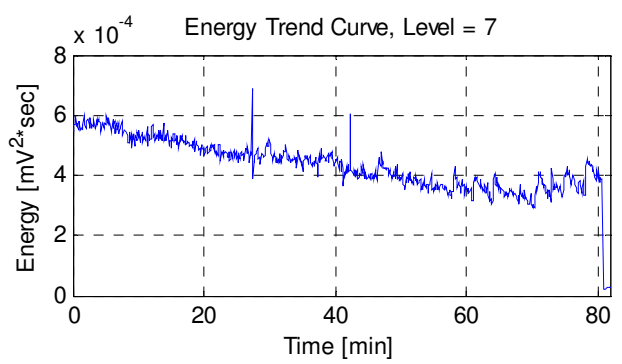

(g) Level 7

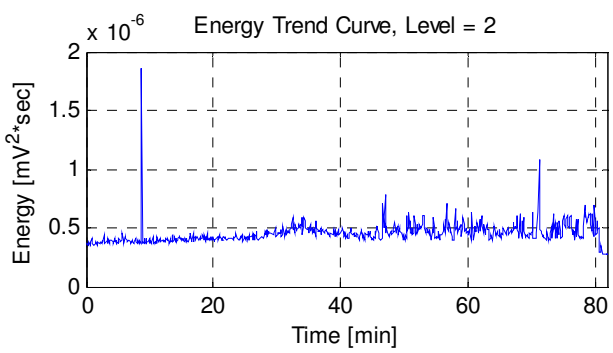

(b) Level 2

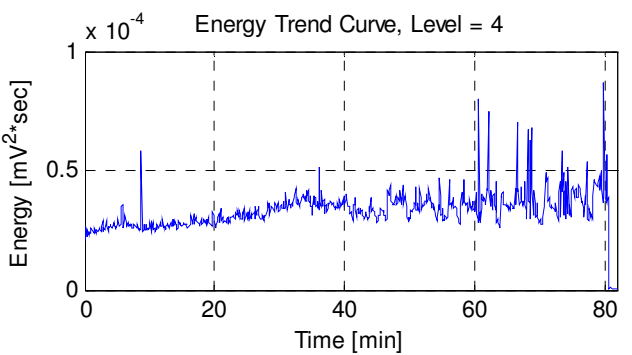

(d) Level 4

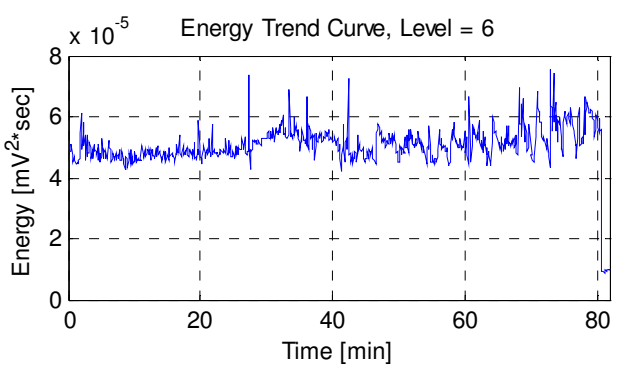

(f) Level 6

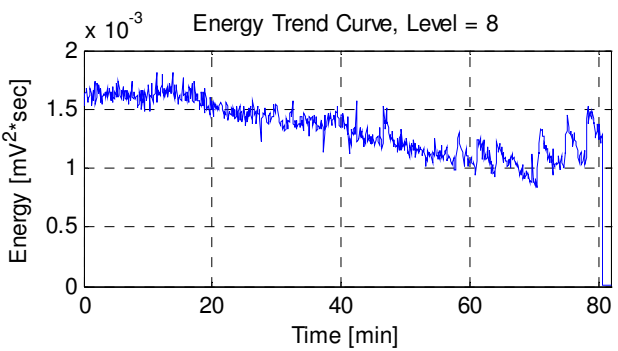

(h) Level 8

Fig. 15. PAC energy trend of each wavelet level 


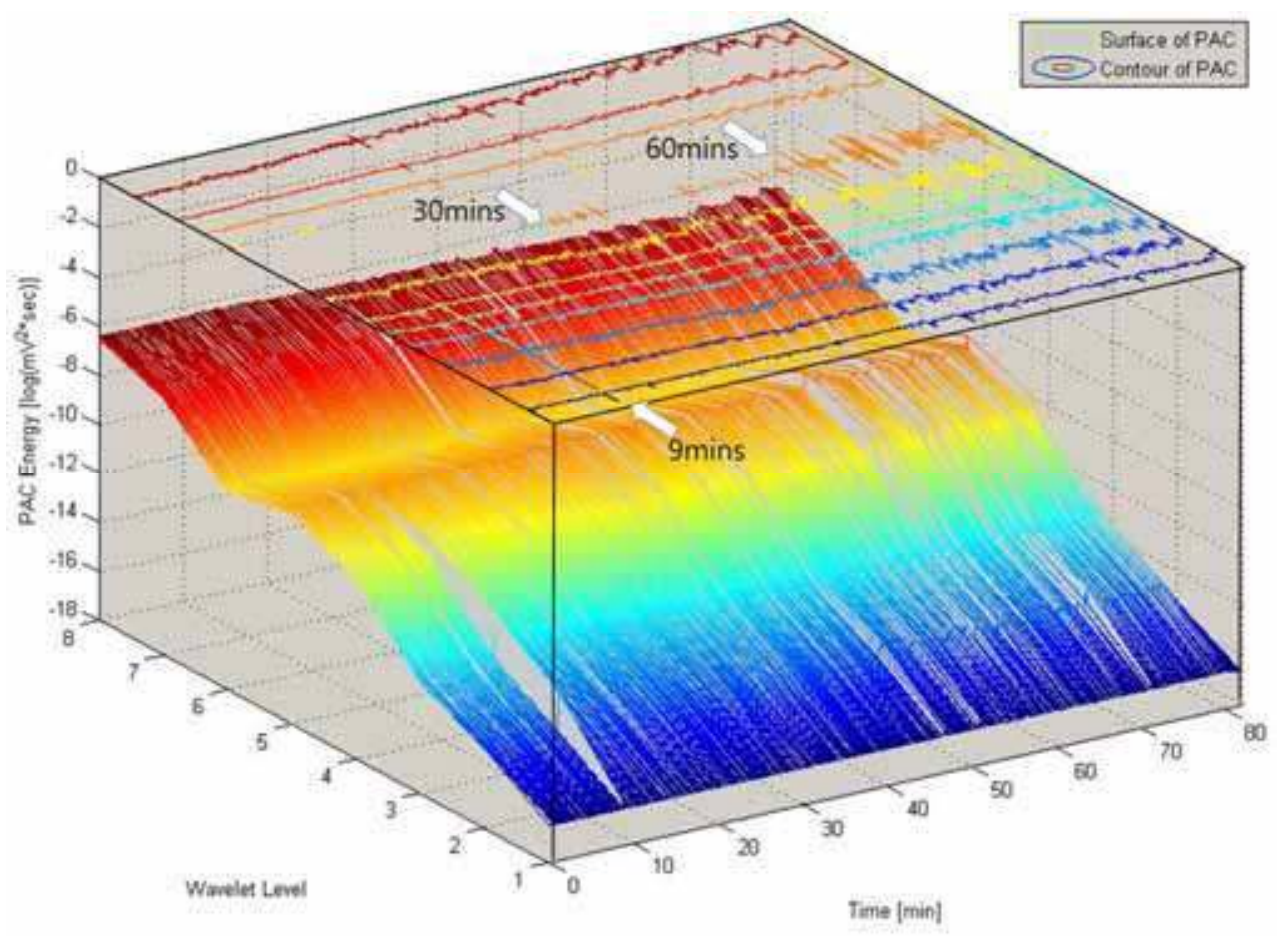

Fig. 16. PAC-Energy level of total wavelet level

To compare absolutely the energy of each wavelet level, all of PAC energy was displayed on a 3D graph with time and wavelet levels as shown in Fig. 16. In wavelet level 5, after approximately 30 minutes, a large transient rise in PAC energy level was observed and this AE activity gradually observed frequently after 60 minutes until the shaft was fractured. In addition, a peak created at 9 minutes was indicated. In here, we could consider that the frequency range of wavelet level 5 could be shown a good relationship between the PAC energy and the crack growth of the middle and final stage. Even so, the trend of the wavelet level 7 and 8 was not clearly connected with the others because the frequency range of wavelet level 7 and 8 was lower than the useful frequency range $(100 \mathrm{kHz}$ to $1 \mathrm{MHz})$ of $\mathrm{AE}$ sensor for this research.

Therefore, the AE signal caused by the crack growth was generated on the whole ultrasound frequency range; the initial crack could be detected using the PAC energy on wavelet level 1 to 4 . In addition, it could be presented on wavelet level 5 until the fracture of the shaft. In the frequency domain, it was shown that the harmonic components of the rotating speed and bearing cage frequency were excited by the crack growth, especially on the $3 \mathrm{X}$ $(28.6 \mathrm{~Hz})$ and $31 \mathrm{~Hz}$.

\section{Conclusion}

In this paper, a signal processing method for AE signal by envelope analysis with discrete wavelet transforms is proposed. For the detection of faults generated from a gear system 
using the suggested signal processing, a gearbox was installed in the test rig system. Misalignment was created by twisted case caused by arc-welding to fix the base and bearing inner race fault is generated by severe misalignment. To identify the sensing ability of the $\mathrm{AE}$, vibration signal was acquired through accelerometer and compared to the $\mathrm{AE}$ signal. Also, to find the advantage of the proposed signal processing method, it was compared with traditional envelope analysis.

According to the experiment result, AE sensor can detect the fault earlier than an accelerometer because of high sensitivity and in the power spectrum, the harmonics of the rotating speed and the gear mesh frequency clearly occurred. Misalignment was observed and bearing faults were also detected in the early fault stage. The proposed envelope analysis is worked to evaluate the faults and indicated the faults frequencies, rotating speed, sideband of BPFI, gear mesh frequency and harmonics, explicitly.

For the detection of the crack growth on the shaft, a cracked shaft was installed on the test rig, and the crack was seeded by wire-cutting with $0.5 \mathrm{~mm}$ depth. The cracked shaft was lifted $6.5 \mathrm{~mm}$ by the lifting tool. The AE signals were transformed by FFT to create the power spectrums, and in the spectrums several peaks were occurred by the crack growth. Along the growth of the crack, the characteristic of the power spectrum was changed and displayed different frequencies.

In the power spectrum, it was shown that the harmonic components of the rotating speed and bearing cage frequency were excited by the crack growth as shown in the Fig. 6, especially on the $3 \mathrm{X}(28.6 \mathrm{~Hz})$ and $31 \mathrm{~Hz}$. And the AE signal caused by the crack growth is generated on the whole ultrasonic frequency range; the initial crack could be detected using the PAC-Energy on wavelet level 1 to 4, and after that, it could be presented on wavelet level 5 until the fracture of the shaft. Therefore, in this paper, it could be shown that the crack growth in rotating machinery is able to be considered and to be detected; in addition, PAE-Energy can be used to detect the early detection of the crack.

Therefore, the proposed signal processing method that is the envelope analysis intercalated DWT using Daubechies mother function between BPF and wave rectification can be shown to provide better result than traditional envelope analysis.

\section{Acknowledgment}

This work has been supported by Basic Science Research Program through the National Research Foundation of Korea (NRF) funded by the Ministry of Education, Science and Technology (2011-0013652) and the 2nd Phase of Brain Korea 21.

\section{References}

Burrus, C.S., Gopinath, R.A. \& Guo, H. (1997). Introduction to wavelet and wavelet transforms: A Primer, Prentice-Hall, ISBN 0134896006, Upper Saddle River, NJ.

Douglas, H. \& Pillay, P. (2005). The impact of wavelet selection on transient motor current signature analysis, Proceedings of 2005 IEEE International Conference on Electric Machines and Drives, ISBN 0780389875; 978-078038987-8, San Antonio, TX, May 2005.

Hatch, C.T. \& Bently, D.E. (2002). Fundamentals of Rotating Machinery Diagnostics, Bently Pressurized Bearing Press, ISBN 0-9714081-0-6, Minden, NV. 
James, E. \& Bery, P.E. (1994). IRD Advancement Training Analysis II: Concentrated Vibration Signature Analysis and Related Condition Monitoring Techniques, IRD Mechanalysis Inc., Columbus, Ohio.

Kim, Y.H., Tan, Andy. C.C., Mathew, J., Kosse, V. \& Yang, B.S. (2007). A comparative study on the application of acoustic emission technique and acceleration measurements for low speed condition monitoring, 12th Asia-Pacific Vibration Conference, Hokkaido Univ. Japan, August 2007.

Kim, Y.H., Tan, Andy. C.C., Mathew, J. \& Yang, B.S. (2005). Experimental study on incipient fault detection of low speed rolling element bearings: time domain statistical parameters, 12th Asia-Pacific Vibration Conference, Hokkaido Univ. Japan, August 2007.

Li, H., Zhang, Y. \& Zheng, H. (2009). Gear fault detection and diagnosis under speed-up condition based on order cepstrum and radial basis function neural network, Journal of Mechanical Science and Technology, Vol. 23, No. 10, (October 2009), pp.27802789, ISSN 1738494X.

Mba, D. \& Bannister, R. H. (1999). Condition monitoring of low-speed rotating machinery using stress waves: Part 1 and Part 2, Journal of Process Mechanical Engineering. Vol. 213, No. 3, (1999), pp.153-185, ISSN 0954-4089(Print), 2041-3009(Online)

Mba, D., Cooke, A., Roby, D. \& Hewitt, G. (2003). Opportunities offered by acoustic emission for shaft-seal rubbing in power generation turbines; a case study. Conference sponsored by the British Institute of NDT. International Conference on Condition Monitoring, ISBN 1901892174, Oxford, UK, July 2003.

Mba, D., Cooke, A., Roby, D. \& Hewitt, G. (2004). The detection of shaft-seal rubbing in large-scale power generation turbines with acoustic emission; Case study, Proceedings of the Institution of Mechanical Engineers, Part A: Journal of Power and Energy, Vol. 218, No. 2, (March 2004), pp.71-81, ISSN 0957-6509.

Misiti, M., Misiti, Y., Oppenheim, G. \& Poggi, J.M. (2009) Wavelet Toolbox TM 4 user's guide, The MathWorks. Inc., Retrieved from <http:/ / www.mathworks.com >

Ronnie, K.M. \& V. K. Eric, (2005). Nondestructive testing handbook Volume 6; Acoustic Emission Testing, American Society for Nondestructive Testing, ISBN 978-1-57117-137-5, Columbus, Ohio.

Sato, I. (1990). Rotating machinery diagnosis with acoustic emission techniques, Electrical Engineering of Japanese, Vol. 110, No. 2, (1990), pp.115-127, ISSN 04247760.

Sentoku, H. (1998). AE in tooth surface failure process of spur gear, Journal of Acoustic Emission, Vol. 16 No. 1-4, (August 1998) pp.S19-S24, ISSN 0730-0050.

Sheen, Y.T. (2008). An envelope detection method based on the first-vibration-mode of bearing vibration, Measurement: Journal of the International Measurement Confederation, Vol. 41, No. 7, (August 2008), pp.797-809, ISSN 0263-2231.

Sheen, Y.T. (2010). An envelope analysis based on the resonance modes of the mechanical system for the bearing defect diagnosis, Measurement: Journal of the International Measurement Confederation, Vol. 43, No. 7, (August 2010), pp.912-934, ISSN 02632241.

Shiroishi, J., Li, Y., Lian, S., Danyluk, S. \& Kurfess, T. (1999). Vibration analysis for bearing outer race condition diagnostics, Journal of Brazilian Society of Mechanical Science, Vol. 21, No. 3, (September 1999), pp.484-492, ISSN 0100-7386. 
Singh, A., Houser, D. R. \& Vijayakar, S. (1996). Early detection of gear pitting, American Society of Mechanical Engineers, Vol. 88, (1996) pp.673-678, ISSN 15214613.

Siores, E. \& Negro, A.A. (1997). Condition monitoring of a gear box using acoustic emission testing, Material Evaluation, Vol. 55, No. 2, (February 1997), pp.183-187, ISSN 00255327

Tan, C.K. \& Mba, D. (2005). Limitation of acoustic emission for identifying seeded defects in gearboxes, Journal of Non-Destructive Evaluation, Vol. 24, No. 1, (March 2005), pp.1128, ISSN 0195-9298.

Tan, C.K., Irving, P. \& Mba, D. (2007). A comparative experimental study on the diagnostic and prognostic capabilities of acoustics emission, vibration and spectrometric oil analysis for spur gears, Mechanical Systems and Signal Processing, Vol. 21, No. 1, (January 2007), pp.208-233, ISSN 0888-3270

Wu, J.D., Hsu, C.C. \& Wu, G.Z. (2009). Fault gear identification and classification using discrete wavelet transform and adaptive neuro-fuzzy inference, Expert Systems with Applications, Vol. 36, No. 3, (April 2009), pp.6244-6255, ISSN 0957-4174.

Wu, J.D. \& Chen, J.C. (2006). Continuous wavelet transform technique for fault signal diagnosis of internal combustions engines, NDTEE International, Vol. 39, No. 4, (June 2006), pp.304-311, ISSN 0963-8695.

Yang, Y., Yu, D. \& Cheng, J. (2007). A fault diagnosis approach for roller bearing based on IMF envelope spectrum and SVM, Measurement: Journal of the International Measurement Confederation, Vol. 40, No. 9-10, (November 2007), pp.943-950, ISSN 0263-2231. 


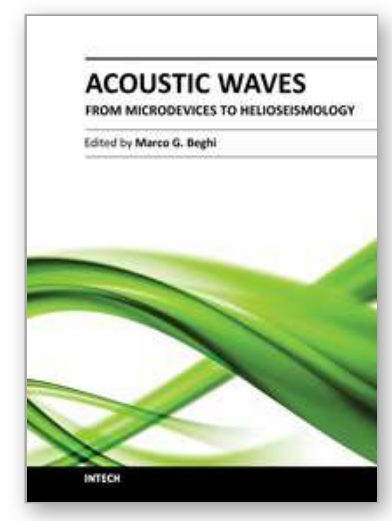

\author{
Acoustic Waves - From Microdevices to Helioseismology \\ Edited by Prof. Marco G. Beghi
}

ISBN 978-953-307-572-3

Hard cover, 652 pages

Publisher InTech

Published online 14, November, 2011

Published in print edition November, 2011

The concept of acoustic wave is a pervasive one, which emerges in any type of medium, from solids to plasmas, at length and time scales ranging from sub-micrometric layers in microdevices to seismic waves in the Sun's interior. This book presents several aspects of the active research ongoing in this field. Theoretical efforts are leading to a deeper understanding of phenomena, also in complicated environments like the solar surface boundary. Acoustic waves are a flexible probe to investigate the properties of very different systems, from thin inorganic layers to ripening cheese to biological systems. Acoustic waves are also a tool to manipulate matter, from the delicate evaporation of biomolecules to be analysed, to the phase transitions induced by intense shock waves. And a whole class of widespread microdevices, including filters and sensors, is based on the behaviour of acoustic waves propagating in thin layers. The search for better performances is driving to new materials for these devices, and to more refined tools for their analysis.

\title{
How to reference
}

In order to correctly reference this scholarly work, feel free to copy and paste the following:

Dong Sik Gu and Byeong Keun Choi (2011). Machinery Faults Detection Using Acoustic Emission Signal, Acoustic Waves - From Microdevices to Helioseismology, Prof. Marco G. Beghi (Ed.), ISBN: 978-953-307-5723, InTech, Available from: http://www.intechopen.com/books/acoustic-waves-from-microdevices-tohelioseismology/machinery-faults-detection-using-acoustic-emission-signal

\section{INTECH}

open science | open minds

\section{InTech Europe}

University Campus STeP Ri

Slavka Krautzeka 83/A

51000 Rijeka, Croatia

Phone: +385 (51) 770447

Fax: +385 (51) 686166

www.intechopen.com

\section{InTech China}

Unit 405, Office Block, Hotel Equatorial Shanghai

No.65, Yan An Road (West), Shanghai, 200040, China 中国上海市延安西路65号上海国际贵都大饭店办公楼 405 单元

Phone: +86-21-62489820

Fax: $+86-21-62489821$ 
(C) 2011 The Author(s). Licensee IntechOpen. This is an open access article distributed under the terms of the Creative Commons Attribution 3.0 License, which permits unrestricted use, distribution, and reproduction in any medium, provided the original work is properly cited. 